\title{
Being There: Participants and Spectators in Interactive Narrative
}

\author{
Ruth Aylett and Sandy Louchart \\ MACS, Heriot-Watt University, Riccarton, Edinburgh. EH14 4AS, UK \\ \{Ruth, Sandy\} @macs.hw. ac.uk
}

\begin{abstract}
This paper considers the problem of evaluating interactive narrative and discusses the storification process through which a narrative is internalised. It establishes the range of roles that a user may take, and argues that the participant/non-participant distinction has a key role in storification. An experiment carried out as part of a larger test of a double appraisal approach to the creation of more dramatic characters is discussed. The results show that spectators and participants mark different stories as the most interesting, showing that this role difference does indeed impact their assessment of a narrative experience. The implications for story evaluation are discussed.
\end{abstract}

\section{Introduction}

This paper reports work carried out as part of an investigation in emergent narrative [2]. By this we mean the creation of story-like experiences in real-time using interaction between intelligent synthetic characters as a generative mechanism. The motive for this work is an attempt to resolve what we have described as the narrative paradox in which pre-authored plot structures conflict with the freedom of action and interaction characteristic of the medium of real-time interactive graphical environments. The central idea is that if a narrative experience can be generated without specifying a detailed plot in advance then the user can, alongside intelligent synthetic actors, jointly take responsibility for the unfolding of the story, and the user's actions become a positive contribution to the narrative experience rather than a potential obstacle to it.

An argument against this approach is that it cannot guarantee narrative structure because allowing characters to interact in real-time does not necessarily generate events that are experienced as narrative. One may respond to this position in a number of ways. For example, table-top and live-action role-play stand as empirical counterarguments given that these are precisely generated by the role-playing activity of human participants as supported and shaped by the human game-master [14, 21]. One may also derive theoretical arguments from the game-master's pre-game work in designing a storyworld and rich characters capable of supporting the later jointly shaped narrative experience [16]. Fruitful analogies can be made with other art forms in which pre-authored structure and presentation-time improvisation are combined, as in a number of 20thC classical music pieces ('In C' by Terry Riley, the progenitor of minimalism, is one example). 


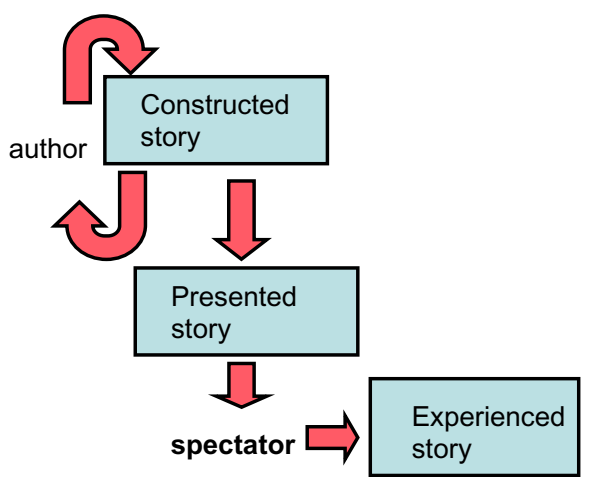

Fig. 1. Conventional narrative

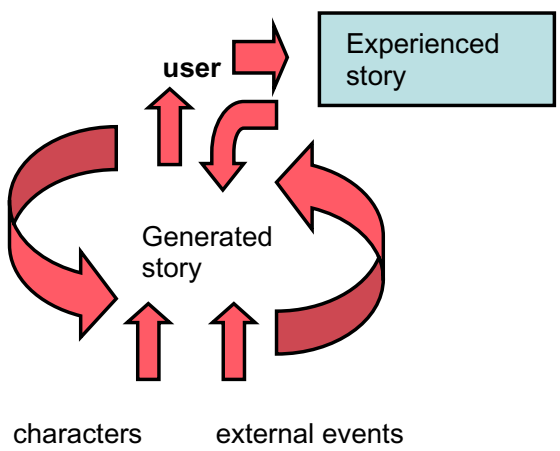

Fig. 2. Interactive narrative

Finally one may respond practically by building and evaluating systems embodying the emergent narrative approach, as in the FearNot! interactive drama on the theme of education against bullying [1]. The last approach is often seen as the most convincing - 'the proof of the pudding is in the eating' - but it raises a further important question: how can one tell if an emergent narrative is successful?

There is in fact no agreed evaluation methodology for interactive narrative in general [20] and formidable problems must be faced in deriving one. Narratology has taken an analytical approach to its field, but analytical decomposition of the story artefact rarely attempts to answer the question of how 'good' a story is, though it may be used post hoc as a theoretical justification for a positive or negative aesthetic judgment. However both aesthetic judgement and supporting structural justifications are closely tied to the existence of a single narrative artefact with separate phases of authoring and presentation as illustrated in Fig. 1. It is an approach that invests heavily in the concept of audience - whether reader or spectator - as an objective evaluative vantage point from which the narrative artefact can be considered. Indeed, a classic view of authorship incorporates such a perspective as the author's desired effect, and while the more recent attack on the priority of author intentionality (the Foucaultian 'death of the author') undermines this linking evaluative function between authoring and presentation phases, if anything it puts still more emphasis on the narrative artefact itself ('the text').

Once interactivity is introduced, this position becomes untenable in our view. If interactivity means anything then the reader/spectator must be translated into the user (for want of a more generally agreed term), who, from the conventional perspective, is able to change the narrative artefact as it is presented, destroying its singular identity. Which then is the artefact that is to be evaluated? One must move from narratology to psychology and consider not the narrative artefact but the process through which the user engages with it and internalises it as a narrative experience - a process we have referred to as storification [2]. Figure 2 illustrates the processoriented structure of interactive narrative. Within this framework, evaluation becomes subjective, contingent and process-oriented rather than objective, universal and artefact-oriented. Translating this into computing terms, the specific user experience and level of satisfaction must be considered, as argued in the case of Façade [12]. In 
principle, it is the storification process itself that ought to figure in evaluation, though accessing it is of course problematic.

\section{Participative Narrative and Storification}

The literature on narrative psychology focuses more on the impact narrative has on the overall psychology of the subject [9], and in particular whether it has lasting affective or cognitive impact, rather than on the process of storification itself. However it has increasingly been argued in the recent period that narrative thinking represents a fundamental structuring of human experience, both individual and collective [22] and that the internalisation of the individual's own past can be represented as an autobiographical memory [4], holding stories about the self.

It is tempting to see in this perpetual storification of individual life-experience the roots of external narrative as a way of socially restructuring autobiographical memory. A consequence of taking autobiographic memory as the basis for storification within narrative experiences, as distinct from ordinary life experiences, is a stress on the primacy of the self and its own actions within storification. The development of a theory of mind (ToM) which allows an individual to in some sense put themselves in the shoes of someone else is one way in which the self-oriented construction of autobiographical memory could be extended into a process engaging with the stories of others. The identification with a story character that is often felt by a spectator when they are narratively engaged might represent evidence of this extension.

However the existence of autobiographic memory as a more primitive structure, supplemented by ToM in order to process narrative as a spectator, suggests strongly that participating in a narrative experience might be experienced quite differently from spectating. Putting it into the context of an interactive narrative, spectating puts the user into the meta-narrative universe where participating forces them to commit to actions as a character within the narrative. As a spectator, characters are observed and ToM is used to infer inner state, for example emotion and motivation. As a participant, the motivation and emotion specific to the character must be felt, at least in imagination, in order to decide upon actions, so that the participating user experiences a commitment to act. From an evaluation perspective then, a story might have quite a different impact on storification and thus on evaluation in these two cases.

A further angle on this difference can be derived from work on systems of thought, originating in analysis of child development and learning [4]. Bruner identifies three specific such systems: enactive, in which a child uses action to manipulate objects; iconic, in which a child employs mental images which are primarily visual or otherwise sensorily-based; and symbolic, using language, reasoning, and other systems of meaning. In a participative narrative, these three systems are coupled very closely by the sense, reflect, act cycle required to act in the story-world, linked by the perspective of the specific role being played. In a spectating role, the input to these systems of thought is quite different, with a much greater importance for perceiving and reflecting over a range of characters, and little or no use of enactive systems. 


\section{Modes of User Engagement}

Having considered in abstract the impact of participation as against non-participation in the story-world, it seems worth examining the actual roles that users play in relation to the narrative experience. Here, it would be a mistake to see interactivity in narrative as a binary attribute rather than a spectrum. At the non-interactive end is the conventional spectator or audience. At the completely interactive end is the participant user in a generative - or emergent - narrative. In between one can distinguish different degrees of coupling with the story-world at presentation time. The table below lists intermediate positions on this spectrum, each of which can be seen in specific software systems built by researchers as well in other media.

Table 1. User roles across a spectrum of interactivity

\begin{tabular}{|l|l|}
\hline Degree of interactivity & Example \\
\hline None & Conventional audience/spectator \\
\hline Non-participant control & Conventional authoring \\
\hline Non-participant influence & $\begin{array}{l}\text { Forum Theatre spect-actors; Deus } \\
\text { ex machina; many God games }\end{array}$ \\
\hline Participant control points & Branching narratives \\
\hline $\begin{array}{l}\text { Freely participating } \\
\text { character }\end{array}$ & LARP, Emergent narrative \\
\hline
\end{tabular}

Non-participant control is merely the reverse side of the audience/spectator: the author does not appear within the narrative experience but rather determines it with a control reaching variably down an abstraction hierarchy from overall theme, through abstract action sequences to details of character behaviour [2]. Film is the most extreme example given that the director may control even the detailed expressive behaviour of actors through the use of multiple cuts and editorial composition of the final artefact. Multi-media authoring typically also belongs in this class.

Non-participative influencing allows the user to retain the objective aspects of the audience while simultaneously taking a degree of authorial responsibility for the overall narrative experience and typically interleaves interactive and non-interactive phases. It covers a variety of forms in which the user does not directly participate in the narrative experience but nevertheless lacks full control over its unfolding, either because events outside of their control are simulated, or because characters have a degree of autonomy. 'God-games' such as The Sims are one example of this user role, but an interesting variant can be found in the spect-actors of Forum Theatre [3]. Here a section of the audience is allocated a character in the unfolding drama - the actor, playing in role - and meets with them to discuss what has happened in the previous episode and what they ought to do in the following episode. The actor will take the advice of their audience section unless it conflicts with their role, and is also allowed to halt an episode if it seems that further advice is needed. A version of this approach was implemented in the anti-bullying FearNot! system [1], in which episodes are 
generated as emergent narratives by synthetic characters but the user interacts with a victimised character between episodes and advises them.

It is also possible to act as a non-participant influencer by generating events exogenous to the characters [5] that impact their goals and force re-planning, by, for example, removing resources required by their current plan. The game-master of roleplaying games may adopt either of these approaches: their use of non-player characters is well short of participation since they are essentially disposable vehicles for influencing the human players in specific ways.

Branching narrative can be seen as a minimally interactive form of participation. It allows a set of pre-authored possibilities to be navigated through decisions by the user at specific choice points, thus isolating interactive possibilities from non-interactive story-elements. This distinction becomes very clear in computer games in which entirely scripted cut scenes are interleaved with interactive choices which may themselves not result in much, if any, narrative structure. It has however been used effectively in pedagogically oriented systems [17] where meeting educational objectives may require this degree of authorial control at the expense of interactive freedom

As one moves from the interleaving of interactive and non-interactive narrative components in a branching narrative, to the emergent narrative framework, interactivity becomes the determining influence on the user experience. For this reason, there are in principle as many stories as there are characters, since when dramatic interest is generated by character interaction, if every character has a narrative experience then by definition a participating user playing the role of any character will have one.

\section{An Experiment in User Role and Evaluation}

We have argued above that the participant and non-participant roles result in basic differences in the storification process. If true, then it must be taken into account in evaluating interactive narrative since the invisible internal structures that are being evaluated may well differ. In order to establish whether this is so in practice, we conducted an experiment using an emergent narrative system based on the FatiMA agent architecture [6] used in the FearNot! application already mentioned - see Fig. 3.

FatiMA is an autonomous agent architecture driven by cognitive appraisal, which generates internal emotional states using the OCC taxonomy [18] and links these to coping actions [13] generated both as emotionally-driven reactions and emotionallydriven planning $[7,8]$. The detail of this architecture is not germane to the evaluation reported here but has been reported elsewhere [1]; it supports emergent narrative generated by interaction between characters each with a separately-configured instance of FatiMA as their 'mind'.

An entirely new scenario was created involving a group of characters with sharply conflicting goals exploring an Egyptian pyramid that turns out eventually to contain an alien spaceship. Although a graphical visualisation system can be linked to FatiMA characters, as was the case in FearNot!, in this instance a text-based visualiser was used to avoid the considerable effort involved in generating graphical assets. 


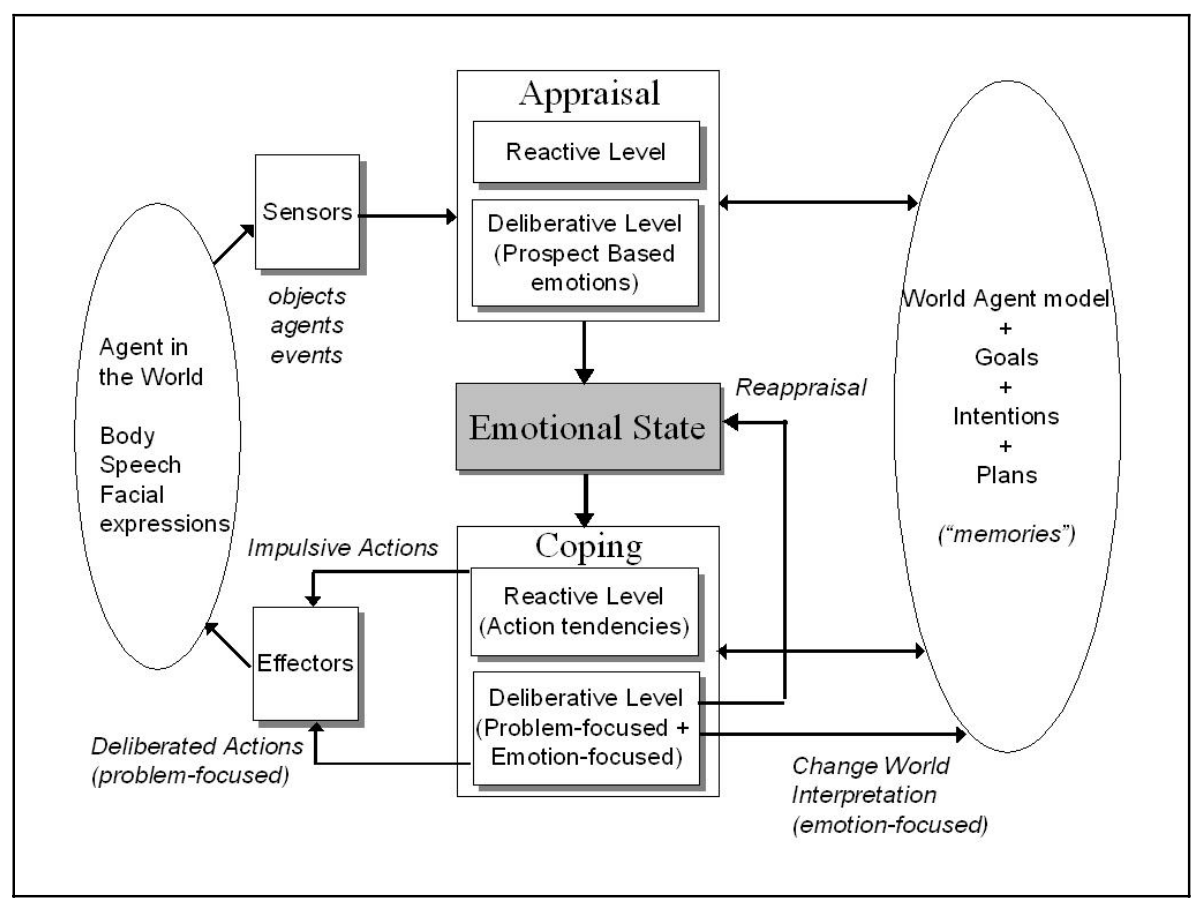

Fig. 3. The FAtiMA agent architecture

Two variants on the architecture of Fig. 3 were developed. In the first of these, characters were given the ability to evaluate the emotional impact of the set of actions they were considering by assuming that other characters would react as they did themselves. This involved relabelling actions as events and running them a second time through the agent mind as if they had happened to the character rather than being carried out by the character - a double appraisal approach. This allowed the action with the greatest emotional impact to be chosen. In the second variant, double appraisal was carried out using the actual minds of other characters in the scene possible in a graphical world as it is not in the real world.

Different stories using this scenario (identical set and initial character definitions) are generated by the system on different occasions depending on which FAtiMA variant is implemented in the agent minds, due to the impact this has on the actions selected by characters. A further element of indeterminacy is added by the stochastic outcome of some physical actions, so that for example a character who is shot may be killed or may be just wounded. To take these variations into account, and also in order to prevent the user interface design from affecting results, the system was used to exhaustively generate all possible versions of a single short scene to be used for evaluation. This turned out to produce five distinct stories in the form of sets of language and non-language actions. The language actions were turned into text by 
hand by manually applying a standard templating approach used within FearNot! Of the resulting stories, number 3 and number 5 can be seen below in Appendix 1 .

As previously mentioned, the evaluation of stories is an open research question. To date, apart from an interview-based study for a non-implemented system by Kelso et al [11], very little has been done in order to assess the intrinsic quality of a story. Much of the evaluation work for interactive storytelling systems has instead been oriented towards character believability or user interest in replaying stories [20, 12]. This study aimed to provide results that robustly support comparison with other work in the field and as a result sought to establish the statistical significance of those results. The one-Way-ANOVA approach was selected from other possible statistical approaches, as it is generally suitable for tests with similar data ranges to the ones in this study. The assumption was made that the differences between samples were normally distributed. Results have been subject to an analysis of variance (ANOVA) and are statistically significant to a 0.1 range $^{1}$ within the evaluation test batches. The probability of insignificance (p) and degree of significance $(\% \mathrm{R})$ are indicated for each result.

46 subjects (M 32 F 14) carried out a number of ranking and marking exercises with the five stories, of which two are the subject of this discussion. The table below details the participants' distribution.

Table 2. Participant distribution

\begin{tabular}{|c|l|l|l|}
\hline & Male & Female & Total \\
\hline Interactive & 22 & 8 & 30 \\
\hline Non-interactive & 10 & 6 & 16 \\
\hline Experts & 10 & 1 & 11 \\
\hline Non-Experts & 22 & 13 & 35 \\
\hline
\end{tabular}

The evaluation plan designed for this application was composed of 5 different tests that aimed towards assessing the dramatic values of the stories generated by the system. T1 and T2 aimed to assess stories from a spectator perspective by presenting the user with a set of stories and asking them to mark and rank them by order of preference. Although T1 and T2 displayed the same stories to their test audience, these were slightly modified in $\mathrm{T} 2$ so that all stories contained the same amount of actions and therefore were of equal length. This was to establish whether the length of stories plays a role in the marking or ranking by the user. The actions used to lengthen the stories did not influence the appreciation of stories as none of them were reported as being either interesting or meaningful. The final three tests (T3, T4 and T5) aimed to assess stories from a participative perspective and presented the users with a role to play by making decisions for the game-master (T3) and one character (T4, T5) in every cycle. The user was presented with scenario situations and was asked to make decisions, which influenced the outcome of the overall story. Therefore, the users determined from their decisions, the story they experienced. These stories were also marked by users.

\footnotetext{
${ }^{1}$ Note that the 0.1 range is a non-standard statistical measure. However this approach suited the work carried out in this study.
} 
Test A (T1/T2): Subjects read the set of stories generated by the system Test B (T4/T5): Subjects played the role of the colonel and took decisions for him In both cases, subjects:

a. Marked each on a scale 1-5 for dramatic interest and ranked them

b. Marked a certain number of actions for their meaningfulness (1-10 scale)

c. Marked a certain number of actions for their dramatic interest (1-10 scale)

The results can be seen in Fig. 4 below (Participation 46 Male (32) / Female (14) $-\mathrm{p}=$ $0.091 / 90.9 \% \mathrm{R})$

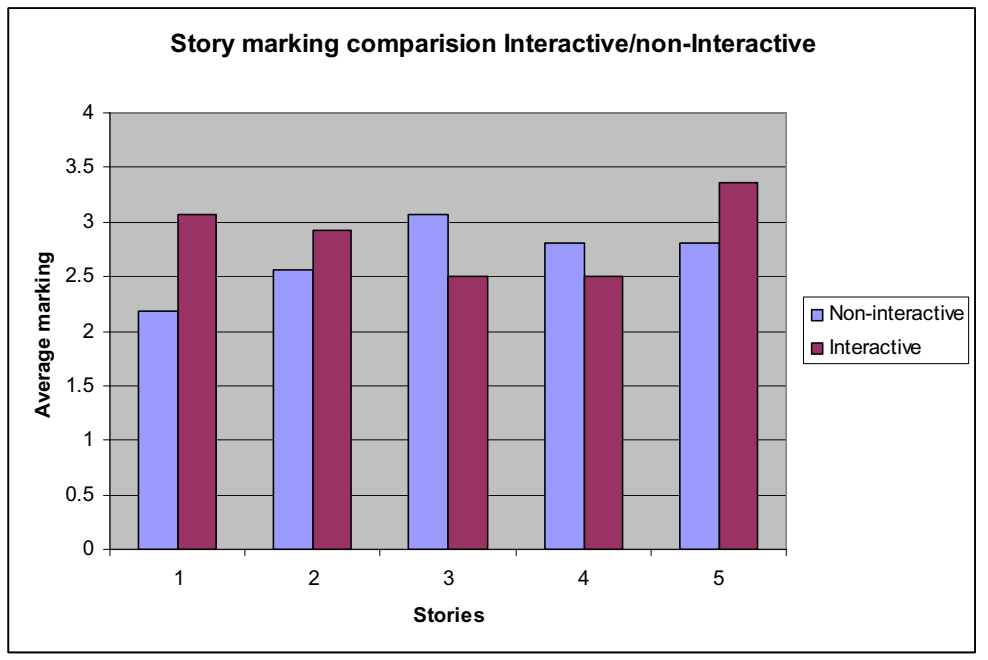

Fig. 4. Non-interactive and interactive marking of stories 1-5

Stories 1, 2 and 5 benefited from interactivity, and presented interactive markings that are significantly higher than their non-interactive counterparts. On the other hand, stories 3 and 4 display the inverse trend. Story 3 presents the best average in noninteractive marking, but only scores joint fourth in interactive marking. Story 5 presents the third best average in non-interactive marking but is first in interactive marking.

The effect of participation as against non-participation is clear in this experiment, though it is not at all clear exactly what in the stories causes this difference. The colonel takes more actions in story 5 including killing one of the party, and it may be that having to take the decision to do this increases the feeling of responsibility for what happens in the scene on the part of the user, or produces more highly emotionally-tagged elements in autobiographical memory. We have not yet found any experimental work in psychology that might clarify this finding, but modelling autobiographical memory, as has been done within FearNot! characters, though not within the scenario discussed here [10], suggests that very different structures would result from carrying out such an action and from observing it. The results cited do 
however make it clear that, as we argued above, if the experience of the user is seen as a key evaluation criterion, participative narrative must be evaluated through participation and not through spectating.

\section{Conclusions and Further Work}

In this paper we have reported an initial experiment in assessing the impact of participation in an interactive narrative on its evaluation. We have hypothesized that this result is related to the differences in the storification process we would expect to find in these two cases, especially if we relate storification to the construction of autobiographical memory. A further search of literature in psychology is required to establish whether existing experimental work can help to explain this result.

Another avenue could be explored by incorporating autobiographical memory into the characters, comparing the changes in a character that carries out an action and a character that observes it. This approach may provide interesting indications of the weight specific story-elements might have in the human mind, but one must add that it does not take account of the element of projection and imagination in the human engagement with narrative - the user is well aware that this is indeed narrative and not real life.

The result of the experiment described does however suggest very clearly that evaluating a participative narrative by observation is likely to provide very misleading results and that there is no alternative to trying to assess the experience of the participating user. Physiological monitoring, already used for evaluation of interaction with conversational synthetic characters [19] might be worth investigating here.

\section{References}

[1] Aylett, R.S., Louchart, S., Dias, J., Paiva, A., Vala, M., Woods, S., Hall, L.: Unscripted Narrative for affectively driven characters. IEEE Journal of Graphics and Applications 26(3), 42-52 (2006)

[2] Aylett, R., Louchart, S.: Towards a narrative theory of VR. Special issue on storytelling. Virtual Reality Journal 7, 2-9 (2003)

[3] Boal, A.: Theatre of the Oppressed. Theatre Communications Group, New York (1979)

[4] Bruner, J.: The Narrative Construction of Reality. Critical Inquiry 18(1), 1-21 (1991)

[5] Cavazza, M., Charles, F., Mead, S.J.: Character-Based Interactive Storytelling. IEEE Intelligent Systems 17(4), 17-24 (2002)

[6] Dias, J., Paiva, A.: Feeling and Reasoning: a Computational Model. In: Bento, C., Cardoso, A., Dias, G. (eds.) EPIA 2005. LNCS (LNAI), vol. 3808, pp. 127-140. Springer, Heidelberg (2005)

[7] Elliot, C.: The Affective Reasoner: A process model of emotions in a multi-agent system. $\mathrm{PhD}$ Thesis, Illinois (1992)

[8] Gratch, J., Marsella, S.: Tears and fears: Modeling emotions and emotional behaviors in synthetic agents. In: The Fifth International Conference on Autonomous Agents (2001)

[9] Green, M.C., Strange, J.J., Brock, T.C. (eds.): Narrative Impact: Social and Cognitive Foundations. Lawrence Erlbaum, Mahwah (2002)

[10] Ho, W.C., Dias, J., Figueiredo, R., Paiva, A.: Agents that remember can tell stories: integrating autobiographic memory into emotional agents. In: AAMAS. Proceedings of Autonomous Agents and Multiagent Systems, ACM Press, New York (2007) 
[11] Kelso, M., Weyhrauch, P., Bates, J.: Dramatic presence. PRESENCE: The Journal of Teleoperators and Virtual Environments, MIT Press 2(1) (1992)

[12] Knickmeyer, R., Mateas, M.: Preliminary evaluation of the interactive drama facade. In: Conference on Human Factors in Computing Systems 2005 (2005)

[13] Lazarus, R.: Emotion and adaptation. Oxford University Press, NY (1991)

[14] Louchart, S., Aylett, R.S.: Solving the narrative paradox in VEs - lessons from RPGs. In: Rist, T., Aylett, R., Ballin, D., Rickel, J. (eds.) IVA 2003. LNCS (LNAI), vol. 2792, pp. 244-248. Springer, Heidelberg (2003)

[15] Louchart, S., Aylett, R.S.: Evaluating synthetic actors. In: Proceedings, AISB Symposia 2007, University of Newcastle, April 2007, pp. 439-445 (2007)

[16] Louchart, S.: Emergent Narrative - towards a narrative theory of Virtual Reality. PhD thesis, University of Salford (2007)

[17] Marsella, S., Johnson, W.L., LaBore, C.: Interactive Pedagogical Drama. In: The 4th International Conference on Autonomous Agents (2000)

[18] Ortony, A., Clore, G., Collins, A.: The cognitive structure of emotions. Cambridge University Press, Cambridge (1988)

[19] Prendinger, H., Becker, C., Ishizuka, M.: A study in users' physiological response to an empathic interface agent. International Journal of Humanoid Robotics 3(3), 371-391 (2006)

[20] Riedl, M., Young, R.M.: An objective character believability evaluation procedure for multi-agent story generation systems. In: Panayiotopoulos, T., Gratch, J., Aylett, R., Ballin, D., Olivier, P., Rist, T. (eds.) IVA 2005. LNCS (LNAI), vol. 3661, pp. 278-291. Springer, Heidelberg (2005)

[21] Tychsen, A., Hitchens, M., Brolund, T.: The Game Master. In: Proceedings of The Interactive Entertainment Conference 2005, Sydney, Australia (2005)

[22] Young, K.: The Neurology of Narrative. SubStance - Issue 94/95 30(1\&2), 72-84 (2001) 


\section{Appendix 1 - Story 3 and Story 5}

\begin{tabular}{|c|c|}
\hline Speaker & Story 3 and Story 5 are identical to start with \\
\hline Colonel & $\begin{array}{l}\text { Let's be clear about what we are all about to do! No one has ever been down } \\
\text { there! Our intelligence reported this site has a potential } \\
\text { threat to our land security! We all know why we are here today! The technology } \\
\text { possibly hidden in there is all that matters to us. In the unlikely event of an } \\
\text { encounter of any type, we are to wipe this place down and make sure no one or } \\
\text { nothing ever come out of this temple! Dead or alive! }\end{array}$ \\
\hline Colonel & $\begin{array}{l}\text { God bless you all. Military personnel in formation, the others behind me, keep an } \\
\text { eye for traps, and do not lose sight of each other. All right, let's go! }\end{array}$ \\
\hline Lieutenant & Yes Sir! \\
\hline Sergeant & Following your order Sir! \\
\hline Professor & Yes sir, yes! \\
\hline Doctor & OK Sir! \\
\hline \multirow[t]{2}{*}{ Researcher } & Following your order Sir! \\
\hline & $\begin{array}{l}\text { Colonel - Explores temple; Lieutenant - Explores temple; Sergeant - Explores } \\
\text { temple; Professor - Explores temple; Doctor - Explores temple; Researcher - } \\
\text { Explores temple }\end{array}$ \\
\hline Speaker & Story 3 \\
\hline Researcher & $\begin{array}{l}\text { Colonel!, Here!, Here come here.. I have something odd here; it looks like a metal } \\
\text { door with strange writings on top of it! }\end{array}$ \\
\hline Colonel & $\begin{array}{l}\text { Lieutenant! Have you got any idea what these inscriptions might } \\
\text { mean? }\end{array}$ \\
\hline Lieutenant & $\begin{array}{l}\text { Colonel, these seem to be the same symbol set we recovered in } \\
\text { New-Mexico. I couldn't translate it into the details but it seems to refer } \\
\text { to some sort of farm land or exploitation next to a digit symbol by the look of } \\
\text { things!. The last line reads the sun must meet the eye! Not sure what that means! }\end{array}$ \\
\hline \multirow[t]{2}{*}{ Researcher } & $\begin{array}{l}\text { I think I got it Colonel!! If you look down the diagram, it is not an eye, although it } \\
\text { looks like it, but a hole in an eclipse type shape. Just like this door and the small } \\
\text { round shape it has there in the middle. Let me orient the beam of light from my } \\
\text { electric torch directly towards the hole! }\end{array}$ \\
\hline & Door opens! \\
\hline Speaker & Story 5 \\
\hline Doctor & $\begin{array}{l}\text { Colonel, everyone, I have something strange there. There are some writings on this } \\
\text { stone. A strange drawing and some hieroglyphs! }\end{array}$ \\
\hline \multirow[t]{2}{*}{ Doctor } & $\begin{array}{l}\text { Oh my god, this is fascinating, my grandfather was right all along! These are the four } \\
\text { element guardians, they represent ancient gods, prior to the ones to which most of } \\
\text { Egyptian mythology is based upon!. If the predictions are right they shall return within } \\
7 \text { days of their temple being penetrated! By entering this chamber we have } \\
\text { provoked their return! The infidels will all die and I shall trust them with my life! This } \\
\text { family talisman should revive the sacred guardians! }\end{array}$ \\
\hline & Statues start to be animated and move towards the party \\
\hline \multirow[t]{2}{*}{ Colonel } & In the chest, Fire at the red light in the chest! Fire! Fire! \\
\hline & $\begin{array}{l}\text { Statues are not stoppable } \\
\text { Statues kill Lieutenant }\end{array}$ \\
\hline
\end{tabular}




\begin{tabular}{|c|c|}
\hline \multirow[t]{2}{*}{ Colonel } & You stupid weirdo! (to Doctor) \\
\hline & $\begin{array}{l}\text { Colonel - Kills Doctor } \\
\text { Statues stop and break into pieces }\end{array}$ \\
\hline Colonel & $\begin{array}{l}\text { OK nothing to worry about here!. Come on everybody; remember what we are } \\
\text { looking for, a sort of entrance to another chamber! }\end{array}$ \\
\hline Colonel & Here!, Here come here.. Hell man, I think this thing might be real after all. \\
\hline Colonel & $\begin{array}{l}\text { Professor! Do these hieroglyphs there above the door say anything of what might be } \\
\text { behind it? }\end{array}$ \\
\hline Professor & $\begin{array}{l}\text { Hum Yes Colonel!, Well, this is strange, these do not appear to be conventional } \\
\text { hieroglyphs! There are actually two sets of text there. One that can be interpreted as } \\
\text { a death threat to any mortal disturbing the lizard gods, no idea whose these can be! } \\
\text { The other one although it looks like Egyptian hieroglyphs contains many symbols I } \\
\text { have never encountered and does not make any sense to me I am afraid! }\end{array}$ \\
\hline \multirow[t]{2}{*}{ Colonel } & $\begin{array}{l}\text { This is a door, therefore it should open one way or another, look for clues on the } \\
\text { structure of the door and the wall! }\end{array}$ \\
\hline & $\begin{array}{l}\text { Colonel accidentally orients the light beam onto the door and triggers the opening of } \\
\text { the door - End of scene! }\end{array}$ \\
\hline
\end{tabular}

